\title{
Unidades geoambientais do Parque Nacional da Restinga de Jurubatiba, litoral norte fluminense
}

\section{Geoenvironmental units at the Restinga de Jurubatiba National Park, in the north coast of the Rio de Janeiro state}

\author{
Saulo de Oliveira Folharini ${ }^{* *} \bowtie$ iD, Regina Célia de Oliveira ${ }^{1 *} \bowtie$ iD, André Luiz dos Santos \\ Furtado $^{2} \varangle$ (iD)
}

1Departamento de Geografia, Instituto de Geociências, Universidade Estadual de Campinas, Campinas, São Paulo, Brasil

2 Empresa Brasileira de Pesquisa Agropecuária

E-mails: reginacoliveira@ige.unicamp.br (RCO); andre.furtado@embrapa.br (ALSF)

*E-mail para correspondência: sfolharini@gmail.com

Recebido (Received): 11/04/2019 Aceito (Accepted):01/02/2020

\begin{abstract}
Resumo: Com objetivo de minimizar as intervenções humanas no ecossistema de restinga, foi instituído, em 29 de abril de 1998, o Parque Nacional (PARNA) da Restinga de Jurubatiba, localizado na faixa costeira de parte dos municípios de Macaé e Quissamã e em toda a faixa costeira do município de Carapebus, no Estado do Rio de Janeiro. Neste cenário, o estudo da paisagem fundamentado na abordagem sistêmica e geoecológica mostra-se um importante instrumento de análise, e embasa estudos de ordenamento territorial e planejamento ambiental. O presente estudo teve como objetivo delimitar e caracterizar Unidades Geoambientais do PARNA da Restinga de Jurubatiba e sua zona de amortecimento terrestre. As etapas de desenvolvimento consideraram a base de dados físicos e antrópicos, formada pelos componentes Formações Geológicas, Compartimentos Geomorfológicos, Classes de Solo, Precipitação e Cobertura da Terra e Uso. Correlacionados, resultaram na delimitação das seguintes Unidades Geoambientais: Colinas altas, Colinas altas dissecadas, Colinas baixas, Colinas baixas dissecadas, Planície lacustre, Planície fluviolacustre, Planície marinha, Planície fluviomarinha, Complexo de lagoas paralelas à costa, Área de inundação e Praia. Ainda como forma de caracterizar a paisagem, foram definidas as funções geoecológicas das Unidades Geoambientais em áreas emissoras, transmissoras e receptoras de matéria e energia. Ao considerar o funcionamento sistêmico, a abordagem de análise geoecológica empregada resultou na delimitação de Unidades Geoambientais que refletem a evolução da paisagem, e o Mapa de Unidades Geoambientais pode ser aplicado na gestão territorial da Unidade de Conservação.
\end{abstract}

Palavras-chave: Análise Geoambiental; Paisagem; Zona Costeira.

Abstract: In order to minimize human interventions in restinga ecosystems, on April 29, 1998, the National Park (PARNA) Restinga de Jurubatiba was established. It is located along the coast in part of the municipalities of Macaé and Quissamã, and along the whole coastal strip of the municipality of Carapebus, in the Rio de Janeiro State. In this scenario, studying landscapes based on a systemic and geoecological approach proves to be an important analytical tool, supporting land-use planning and environmental planning studies. The present work aims to define and characterize geoenvironmental units at PARNA Restinga de Jurubatiba and their terrestrial buffer zone. The development steps considered a physical and anthropic database comprising Geological Formations, Geomorphological Compartments, Soil Classes, Rainfall and Land Use and Cover. When correlated, they enabled the delimitation of the following geoenvironmental units: High hills, Dissected highlands, Low hills, Dissected low hills, Lacustrine plain, Fluvial-lacustrine plain, Marine plain, Fluvio-marine plain, Lagoon complex parallel to the coast, Flood area and Beach. Also, as a way of characterizing the landscape, geoecological functions of geoenvironmental units were defined as areas emitting, transmitting and receiving material and energy. Considering the systemic function, the geoecological analysis approach employed delimited 
geoenvironmental units that reflect landscape evolution, and this database may be applied in territory management at the conservation unit.

Keywords: Geoenvironmental Analysis; Landscape; Coastal Zone.

\section{Introdução}

No continente brasileiro, a paisagem da zona costeira é intensamente transformada pela dinâmica natural de uma área de contato entre continente, oceano e atmosfera (AB'SABER, 2000; RODRIGUEZ et al., 2004). Adicionalmente, as transformações resultantes de uso e ocupação em geral aceleram os processos modificadores da paisagem da zona costeira. A ocupação acelera processos naturais e causa impactos ambientais de ordens escalares diversas. A depender da intensidade e duração do impacto, a área afetada pode demorar milhares de anos para se estabilizar (GUERRA E CUNHA, 2005; MORAES, 2007; MUEHE, 2013).

As zonas costeiras são ambientes de alta fragilidade diante de processos de degradação ambiental. Em decorrência dessa característica, esses ambientes devem ser preservados e ter sua ocupação regularizada e normatizada. Isso só é possível com planejamento territorial prévio, elaborado com base em estudos que considerem: características naturais, que permitem a compreensão da evolução da paisagem, e características humanas, que traduzem a dinâmica de uso, ocupação e exploração dos recursos naturais pelo homem (MUEHE, 2013; RODRIGUEZ et al., 2004).

$\mathrm{O}$ adensamento da ocupação da área de estudo remete ao século $\mathrm{XV}$, com a chegada dos portugueses. Mas é no fim da década de 1950 que ganha grandes proporções, decorrentes da instalação de plantas industriais de setores ligados ao comércio marítimo, para facilitar a exportação de produtos e importação de insumos. O processo de industrialização configura-se como fator de atração populacional, e provoca o aumento do número de habitantes, fator que, somado à falta de planejamento territorial adequado, resultou na ocupação de área inadequadas e desencadeou instabilidades no sistema ambiental (DEAN, 1996; MORAES, 2007).

A economia brasileira, de acordo com o Sistema de Contas Nacionais do IBGE, tem no setor de serviços a representação de 74,6\% do valor adicionado do PIB brasileiro no terceiro trimestre de 2018, seguido pela indústria, com $22,2 \%$ e a agropecuária, com 3,2\%. As atividades econômicas ligadas ao turismo estão enquadradas no setor de serviços. O litoral brasileiro apresenta diferentes áreas de interesse turístico em ambientes naturais formados por processos dinâmicos e climáticos pretéritos, que resultaram em formações como dunas, mangues, lagoas costeiras e praias, nas quais as atividades turísticas desenvolvem-se e têm grande importância na economia local (SOUZA et al., 2009). Segundo Moraes (2007), a ocupação do litoral brasileiro resulta, entre outros fatores, de sua beleza cênica, e se desenvolve estimulada pelo estado, que materializa, na forma de infraestrutura, o necessário para aumentar os fluxos e desenvolver o turismo.

O litoral norte do Estado do Rio de Janeiro, por exemplo, tem cidades de importância regional como Campos dos Goytacazes e Macaé. A região passou por importante ciclo de crescimento econômico, com o aumento das explorações de petróleo na Bacia de Campos, cenário de fundamental importância que embasou o crescimento urbano dessas cidades e o consequente aumento das pressões sobre ambientes litorâneos, como as restingas (FEEMA, 1989). Nesse contexto, foi instituído o Parque Nacional da Restinga de Jurubatiba, com objetivo de proteger um remanescente de restinga no norte fluminense, limitando, dessa forma, a expansão urbana. A importância da instituição de unidades de conservação para mitigar o processo de expansão urbana foi estudada por Silva (2013), que concluiu que as unidades de conservação prestam serviços ambientais fundamentais para a sociedade estabelecida predominantemente próxima a seus limites, como a preservação de nascentes.

As unidades de conservação no Brasil são regulamentadas pelo Sistema Nacional de Unidades de Conservação (SNUC) e classificadas em: conservação integral e uso sustentável. Os parques nacionais (PARNA) enquadram-se nas unidades de conservação integral e têm por objetivo preservar ecossistemas, ou seja, o uso e a ocupação dessas áreas são proibidos (BRASIL, 2000).

O entorno das unidades de conservação, denominado zona de amortecimento, também tem sua ocupação regulamentada pelo SNUC, e essa ocupação não deve afetar a sustentabilidade da unidade (BRASIL, 2000). Dessa forma, usos incompatíveis com o objetivo de preservação não devem ser implantados nessas áreas.

O objetivo das zonas de amortecimento é criar um ambiente intermediário, que minimize impactos ambientais nas unidades de conservação. Entretanto se observa, frequentemente, um cenário de ocupação 
conflitante com as normas estabelecidas para as zonas de amortecimento (BRASIL, 2000; CONAMA, 1990; GALANTE et al., 2002).

No PARNA da Restinga de Jurubatiba, a zona de amortecimento foi delimitada, com base no roteiro de Galante, Bezerra e Menezes (2002), em duas partes, uma terrestre e outra marítima. As características físicas e biológicas que definem a fitofisionomia de restinga, além das características sociais e econômicas de uma região com dinâmica vinculada ao setor petrolífero, foram consideradas para definir os limites da zona de amortecimento terrestre. Já a parte marítima foi delimitada considerando o perfil da Plataforma Continental e a biodiversidade marinha, fundamental para a manutenção do ecossistema (ICMBIO, 2007).

Com objetivo de compreender a estrutura da paisagem e a sua evolução, é proposta a delimitação de Unidades Geoambientais do PARNA da Restinga de Jurubatiba e de sua zona de amortecimento terrestre na escala 1:50.000. As Unidades Geoambientais delimitadas podem ser utilizadas como áreas básicas na gestão do parque e seu entorno, por apresentarem características de funcionamento semelhantes (RODRIGUEZ et al., 2004).

\section{2. Área de estudo}

O PARNA da Restinga de Jurubatiba está localizado (Figura 1) no litoral norte do Estado do Rio de Janeiro em uma área de restinga entre as coordenadas geográficas $22^{\circ} 00^{\prime}$ e $22^{\circ} 23^{\prime} \mathrm{S}$ e $41^{\circ} 15^{\prime}$ e $41^{\circ} 45^{\prime} \mathrm{O}$, tem área de $149,2 \mathrm{~km}^{2}$ e sua zona de amortecimento terrestre tem $386,6 \mathrm{~km}^{2}$.

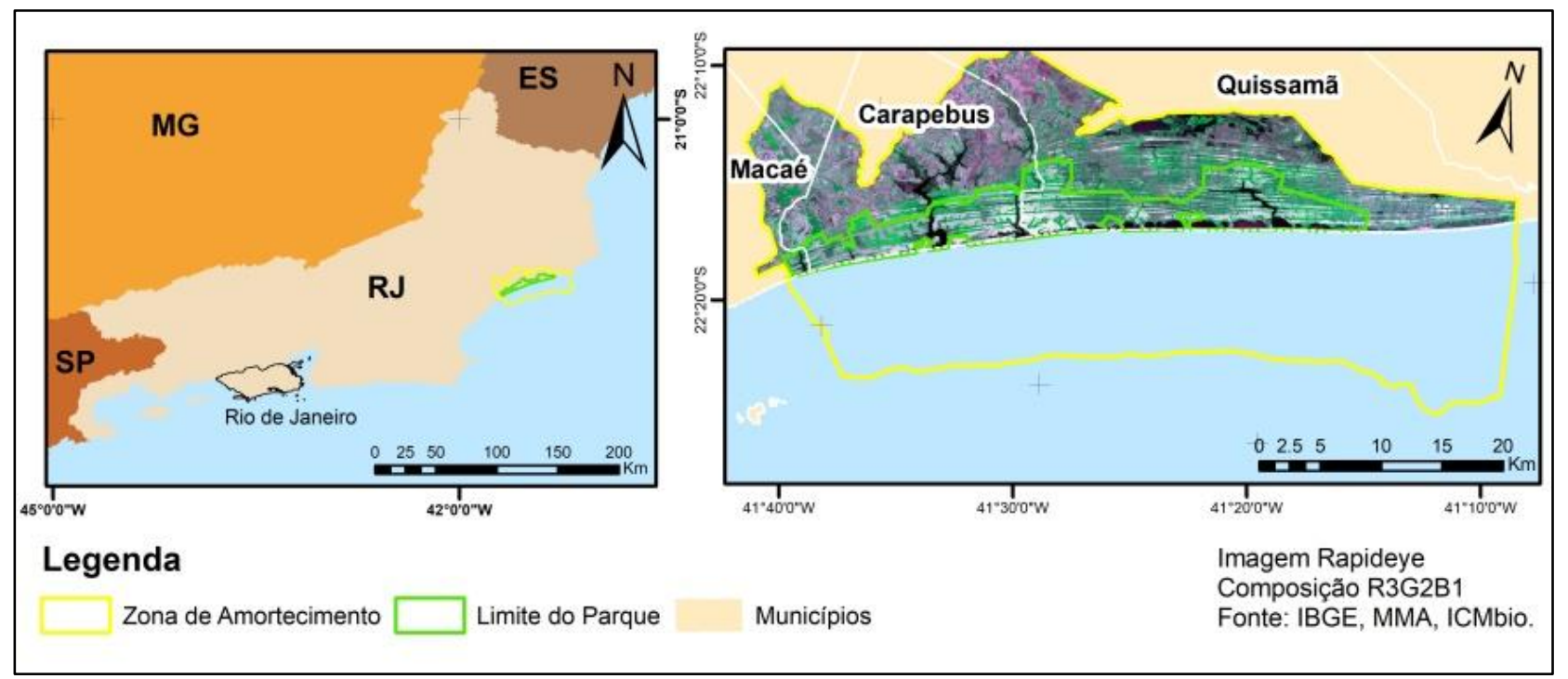

Figura 1: Localização da área de estudo. Imagens RapidEye de 06/01/2014, 10/01/2014, 14/01/2014, 15/01/2014, 21/01/2014 e 28/01/2014. Fonte: IBGE (2015), MMA (2015), ICMbio (2007). Organizado pelos autores.

Predomina o clima Tropical chuvoso (Aw), de acordo com Köppen (1948). A estação chuvosa tem início na primavera, quando a Massa Equatorial Continental avança para o Sul, e tem como resultado fortes chuvas em dezembro e janeiro. Em fevereiro, as chuvas começam a diminuir e inicia-se um período de baixa precipitação que dura até setembro, quando a precipitação volta a aumentar. Os sistemas climáticos atuantes são predominantemente a Frente Intertropical e massas polares nos meses de inverno, as quais reduzem a temperatura e não provocam grande volume de precipitação (BERNARDES, 1957).

Esse seguimento do litoral brasileiro é classificado como Região Oriental ou Leste, macrocompartimento Bacia de Campos, e estende-se de Salvador a Cabo Frio. É limitado a norte pelo Rio Itabapoana e a sul por Cabo Frio (MUEHE, 1998). Nesse macrocompartimento, há a presença dos compartimentos: depósitos quaternários marinhos, eólicos, fluviomarinhos e lagunares, além de afloramentos do escudo cristalino datado do Pré-cambriano, representadas pelos compartimentos Complexo Búzios e Região dos Lagos. Essa área formou-se por processos de deposição de sedimentos em ambiente muito dinâmico, o que a torna de alta instabilidade diante das ações climáticas, do mar e do homem (LAMEGO, 1946; LAMEGO, 1955; MUEHE et al., 2006; MARTIN et. al, 1997). 
A planície de cristas de Praia do Rio Paraíba do Sul é a maior feição geomorfológica desse macrocompartimento. Forma um grande delta e pode ser dividida em dois flancos. Ao norte, por sequência de cristas de Praia de idade holocênica, associadas à atual desembocadura. Ao sul, o flanco de idade pleistocênica é precedido de estreitos cordões litorâneos holocênicos. No interior desse flanco são encontradas áreas de terraços fluviais e zonas pantanosas, remanescentes de fase transgressiva, e um pequeno conjunto de lagoas no interior do cordão litorâneo atual (FOLHARINI E FURTADO, 2014).

Os cordões litorâneos, onde se localiza o PARNA, teriam se formado devido à migração da desembocadura do Rio Paraíba do Sul "... para a posição atual juntamente com a elevação do nível do mar" (MUEHE, 1998, p.284).

Após a formação dos cordões, houve pequena elevação do nível do mar, alagando parte da planície costeira e formando as lagunas, que mantêm conexão permanente ou temporária com o mar por uma barreira, representada por um corpo de areia paralelo à linha de costa (VILLWOCK et al., 2005).

No litoral do Rio de Janeiro, são diferenciados três grandes grupos de lagoas costeiras, conforme sua origem, de acordo com Esteves (1998):

1. Formadas por processos geomorfológicos isolando antigas baías marinhas. Geralmente formando lagoas com água salobra e clara;

2. Formadas a partir da sedimentação da foz de rios drenados para o oceano. São lagoas com água doce ou levemente salobras;

3. Formadas por processo misto, ou seja, ação geomorfológica e sedimentação de rios.

Na área do PARNA da Restinga de Jurubatiba, são encontradas lagoas originadas do processo 2 (ex.: lagoas de Cabiúnas, Paulista e Preta) e processo 3 (lagoas de Carapebus e Comprida).

Nesse ambiente de depósitos sedimentares, ocorrem solos predominantemente de textura arenosa e argilosa. São encontrados solos das classes: Argissolos, na Formação Barreiras; Espodossolos, Gleissolos, Organossolos, nas áreas de planícies fluviais, fluviomarinhas e lagunares; Latossolos, nas áreas de colinas do Complexo Búzios; e areias quartzosas marinhas na Praia (CARVALHO FILHO et al., 2001).

Nessa planície litorânea, também são encontradas algumas áreas urbanas, com ocupação e estrutura diversificada. As ocupações urbanas correspondem aos balneários de Carapebus, João Francisco e Visgueiro, onde populações tradicionais de pescadores estabeleceram-se antes da criação do PARNA. Essa população utiliza as lagoas costeiras, principalmente a Lagoa de Carapebus, como área de pesca. Para preservar esse ambiente e manter o sustento da população pesqueira, foi assinado um termo de compromisso entre o ICMBio e a população (SANTOS, 2008).

Com a criação do PARNA, a expansão do bairro Lagomar, em Macaé, foi interrompida, preservando, assim, o ambiente de restinga. Por ser um bairro por onde passa o canal Macaé-Campos e no qual inexiste sistema de tratamento de esgoto doméstico, parte dos dejetos lançados no canal pode atingir a Lagoa Cabiúnas, dentro dos limites do PARNA, de acordo com estudo realizado por Cordeiro et al. (2011).

\section{Materiais e métodos}

A análise ambiental deve considerar os níveis taxonômicos que determinam a homogeneidade das características naturais, seu funcionamento e estrutura, fundamentais na análise paisagística para entender sua evolução. Para Rodriguez et al. (2004), existem três níveis de análise na superfície geográfica: o global; o regional, com grandes paisagens continentais e regiões geográficas; e o local ou topológico, que evolui com a interação de fatores de ordem planetária e de autodesenvolvimento.

A divisão da paisagem em regiões embasa o desenvolvimento de estudos nas diversas escalas de análise, as quais, ao serem definidas, ocultam ou revelam processos naturais e sociais que ocorrem no território e, dessa forma, direcionam políticas públicas de gestão territorial. A regionalização pode ser feita considerando características econômicas, administrativas, naturais, etc., por meio da classificação e da cartografia de componentes do meio físico. Mas é a regionalização natural, a partir da caracterização do espaço geográfico, que fornece respostas para o entendimento da dinâmica natural do sistema (RODRIGUEZ et al., 2004).

As regionalizações parciais subsidiaram a delimitação das unidades geoecológicas considerando os seguintes pontos: sobreposição das regionalizações parciais (geomorfológica, climática, edáfica, etc.), fator principal (qual característica é mais representativa, com atribuição da importância principal às formações geológicas, porque elas são responsáveis por estruturar e sustentar a paisagem que se formou posteriormente) 
e repetibilidade (como as características se comportam no espaço, os compartimentos e subunidades das regionalizações parciais apresentam áreas distintas, e alguns são mais representativos que outros na totalidade da área de estudo). A aplicação desses pontos nos estudos geoecológicos é fundamental para o entendimento da evolução da paisagem, de possíveis consequências da interação homem/natureza e do desenvolvimento de estudos que visam ao planejamento territorial.

Ao garantir a funcionalidade e estrutura, as paisagens são classificadas conforme sua função geoecológica e podem ser agrupadas em três grandes classes, de acordo com Diakonov (1988): áreas emissoras, responsáveis por garantir o fluxo de matéria e energia para áreas mais baixas do relevo; áreas transmissoras, responsáveis por transmitir os fluxos de matéria e energia das áreas emissoras para as áreas acumuladoras, por exemplo, uma vertente; áreas acumuladoras, onde se acumulam a matéria e energia recebidas de áreas mais elevadas e que são retransmitidas para outras áreas de forma concentrada por canais fluviais, por exemplo, as planícies e os fundos de vale.

Neste estudo, foi utilizada a proposta de Rodriguez et al. (2004) para a análise da paisagem, a qual é dividida em seis etapas: (1) organização, (2) inventário, (3) análise, (4) diagnóstico, (5) proposição e (6) executiva. Para atingir o objetivo, foram consideradas somente as três primeiras etapas.

$\mathrm{Na}$ etapa de organização, foram definidos a escala de análise, a área de estudo e o cronograma de atividades do estudo. Assim, o levantamento de material cartográfico considerou a diversidade de escalas existentes para propor sua adequação para a escala 1:50.000 utilizando imagens de satélite, fotografias aéreas, intepretação visual e edição vetorial. Isso foi necessário devido à heterogeneidade do mapeamento disponível.

$\mathrm{Na}$ etapa de inventário, foram feitas: a interpretação e a adequação da escala das bases cartográficas existentes sobre a temática das formações geológicas, utilizando, para isso, o estudo de Martin et al. (1984), na escala 1:500.000; e a seleção das classes de solo, com base no estudo de Carvalho Filho et al. (2001), na escala 1:250.000. Para ajustar os limites das formações geológicas e classes de solo à escala do presente estudo, 1:50.000, foram utilizadas bases de dados e imagens de satélite RapidEye em escala de maior detalhe (1:20.000), como descrito no estudo de Folharini e Furtado (2014).

Os compartimentos do relevo foram delimitados considerando a proposta de Argento (1995), na escala de 1:50.000. O mapeamento das unidades geomorfológicas foi feito por meio de: interpretação visual de imagens do satélite RapidEye, composição R5G4B3, que, devido ao aumento do contraste, diferencia áreas úmidas de secas; modelo digital do terreno, declividade e relevo sombreado, que auxiliaram a identificar variações altimétricas, mudanças abruptas de declividade e padrões de formas. As etapas da compartimentação do relevo são descritas com mais detalhe no estudo de Folharini et al. (2014).

A precipitação foi analisada no período 2000-2013 utilizando dados do satélite TRMM disponibilizados pelo INPE no site https://www.dsr.inpe.br/laf/series/, pois os dados de precipitação provenientes de estações pluviométricas da ANA e do INMET são de períodos de tempos distintos e apresentam lacunas de dados.

Por fim, o uso e cobertura da terra foi mapeado usando imagens LANDSAT 8 (OLI) obtidas em 02/01/2014 e o método de classificação de máxima verossimilhança, de acordo com a proposta apresentada por Conceição et al. (2016). Foram definidas as seguintes classes: área agrícola, água, areia, floresta de terras baixas, formações arbóreo-arbustivas, formações arbustivo-herbáceas densas, formações arbustivoherbáceas, pastagem, área antropizada e vegetação em área úmida. Esse mapeamento auxiliou na identificação de coberturas vegetais e ocupação humana que contribuem para a estabilidade das formas do relevo ou a vulnerabilidade à perda de solo.

A partir dos dados obtidos nas etapas descritas acima, foi desenvolvida a etapa de análise, com delimitação das Unidades Geoambientais do PARNA da Restinga de Jurubatiba de acordo com o principal impacto ambiental da área, e os processos erosivos, que se relacionam aos componentes naturais e de uso e cobertura da terra, o que permitiu diferenciar as Unidades Geoambientais considerando a função geoecológica de transmissão, recepção ou emissão de matéria e energia.

\section{Resultados e discussões}

A delimitação de Unidades Geoambientais é, segundo a metodologia de Rodriguez et al. (2004), etapa síntese no diagnóstico geoambiental. A delimitação caracteriza o cenário da paisagem atual, definido com áreas de funcionamento semelhantes. Essas características definem uma relação de interdependência sistêmica a partir da troca de matéria e energia em sua função geoecológica (Figura 2). 


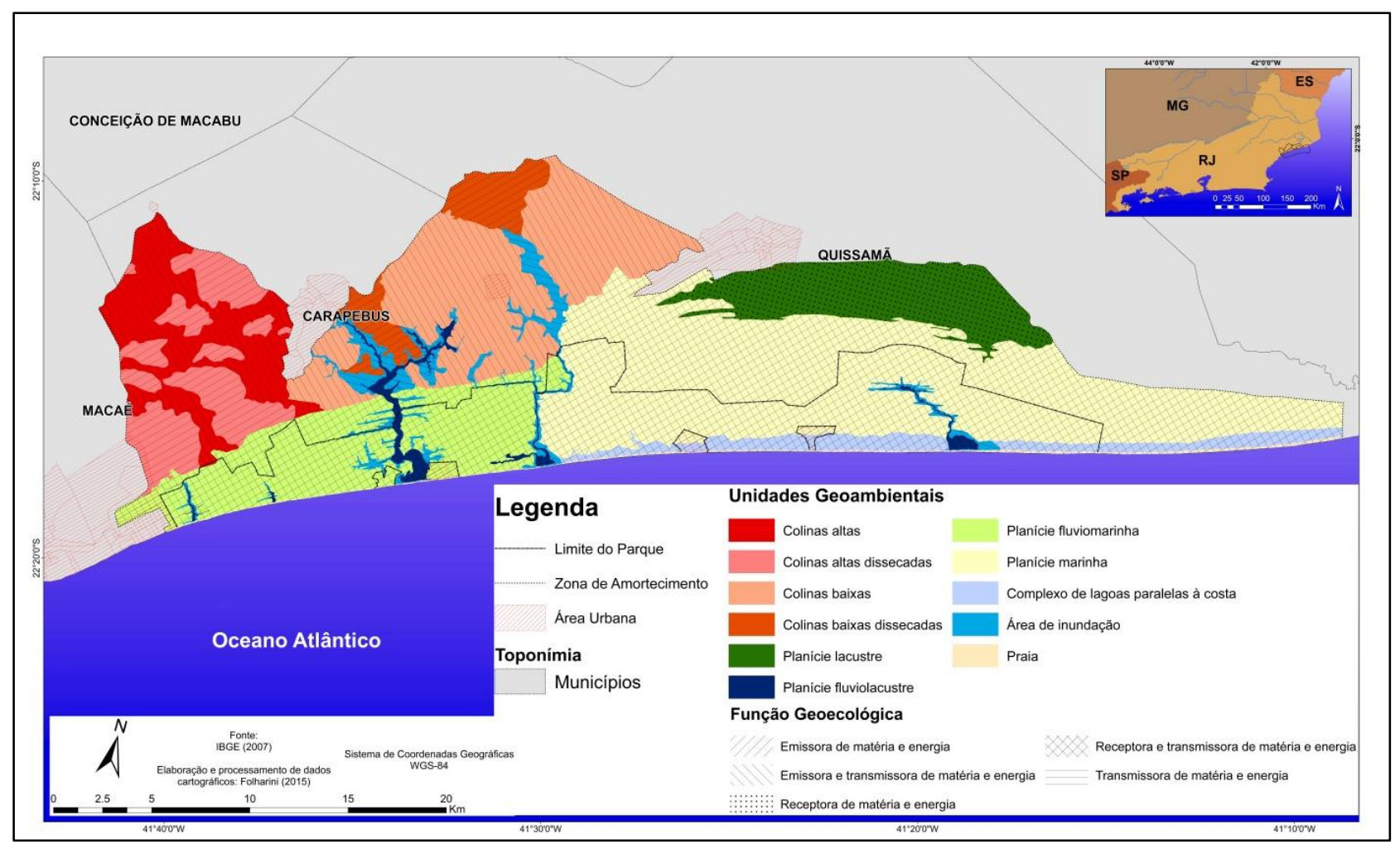

Figura 2: Unidades Geoambientais do Parque Nacional da Restinga de Jurubatiba e da sua zona de amortecimento terrestre. Fonte: Organizado pelos autores (2019).

Cada Unidade Geoambiental, de acordo com sua posição no relevo, tem função geoecológica relacionada à sua característica de emitir, transmitir ou depositar matéria e energia no sistema, e pode enquadrar-se nestas cinco classes:

1. Emissora de matéria e energia: são as áreas mais elevadas, de topos, onde predomina a dispersão de material erodido;

2. Emissora e transmissora de matéria e energia: são emissoras porque estão localizadas em altitudes mais elevadas, de topos, onde predomina a dispersão de material erodido, e são transmissoras, porque incluem áreas com padrão de vertente côncavas onde se concentra o transporte do material e energia;

3. Receptora de matéria e energia: área de planície, caracterizada pelo baixo fluxo de energia devido à declividade reduzida;

4. Receptora e transmissora de matéria e energia: são áreas de contato entre continente/oceano, por exemplo, a Praia, onde este contato favorece a erosão do material depositado e seu retrabalhamento;

5. Transmissora de matéria e energia: áreas de vertentes por onde circula matéria e energia.

Na Tabela 1 são descritas as principais características das Unidades Geoambientais Colinas altas, Colinas altas dissecadas, Colinas baixas e Colinas baixas dissecadas localizadas predominantemente na zona de amortecimento do PARNA da Restinga de Jurubatiba:

A semelhança entre as unidades Colinas altas, Colinas altas dissecadas, Colinas baixas e Colinas baixas dissecadas são as formações geológicas. Há ocorrência da Formação Barreiras, do Complexo Região dos Lagos e da Suíte Desengano. Os solos característicos da Formação Barreiras e de rochas cristalinas, como o Argissolo Vermelho-Amarelo álico, desenvolvem-se em relevo suave ondulado, como as colinas, e necessitam de corretivos e fertilizantes para o desenvolvimento de atividades agrícolas. Os Espodossolos amarelos álicos, que ocorrem em relevos suavemente ondulados, facilitam o pastoreio, mas dificultam a agricultura, porque necessitam de corretivos, devido à baixa disponibilidade de nutrientes minerais. Os Latossolos Vermelhos distróficos, com ocorrência em relevo suave ondulado e plano, têm baixa fertilidade natural e apresentam textura de média a muito argilosa. Resumidamente, os solos necessitam de corretivos para a produção agrícola e, devido à sua textura média a argilosa, são propensos a processos erosivos, dependendo do uso e cobertura. 
Tabela 1: Características das Unidades Geoambientais Colinas altas dissecadas, Colinas altas, Colinas baixas e Colinas baixas dissecadas da zona de amortecimento do PARNA da Restinga de Jurubatiba.

\begin{tabular}{|c|c|}
\hline & Colinas altas dissecadas \\
\hline Formações geológicas & $\begin{array}{l}\text { Formação Barreiras: Depósitos Terciários com relevo tabuleiforme, Complexo Búzios, } \\
\text { Complexo Região dos Lagos, Suíte Desengano. }\end{array}$ \\
\hline $\begin{array}{l}\text { Compartimento } \\
\text { geomorfológico }\end{array}$ & $\begin{array}{l}\text { Forma predominante: topos convexos e } \\
\text { vales abertos. Altitude entre } 90 \text { e } 140 \text { Forma predominante: topos convexos e aguçados. } \\
\text { m. Declividade entre } 8 \text { e } 20 \% \text {. Nas abertos em V. Altitude entre } 90 \text { e } 140 \text { m. } \\
\text { áreas de vale, a declividade pode } \\
\text { alcançar } 45 \% \text {. }\end{array}$ \\
\hline Solos & $\begin{array}{l}\text { Argissolos desenvolvidos no Grupo Barreiras, em rochas cristalinas ou sob influência destas. } \\
\text { Baixa ou muito baixa fertilidade natural. Espodossolos muito pobres em nutrientes minerais. } \\
\text { Textura arenosa predominante. Latossolos muito intemperizados, profundos e bem drenados. } \\
\text { Baixa e alta fertilidade natural. }\end{array}$ \\
\hline
\end{tabular}

Precipitação

Cobertura vegetal

Uso e ocupação

Função geológica
Formação arbustivo-herbácea (moitas menores), formação arbustivo-herbácea densa (moitas densas), arbóreo-arbustiva.

Solo exposto, pastagem, áreas agrícolas e água.

Emissora e transmissora de matéria e energia.

Emissora de matéria e energia.

\begin{tabular}{|c|c|}
\hline & Colinas baixas dissecadas \\
\hline Formações geológicas & $\begin{array}{l}\text { Formação Barreiras: Depósitos Terciários com relevo tabuleiforme, Complexo Búzios, } \\
\text { Complexo Região dos Lagos, Suíte Desengano. }\end{array}$ \\
\hline $\begin{array}{l}\text { Compartimento } \\
\text { geomorfológico }\end{array}$ & $\begin{array}{l}\text { Forma predominante: topos convexos e } \\
\text { vales abertos. Altitude varia entre } 10 \text { e Forma predominante: topos convexos e aguçados. } \\
90 \mathrm{~m} \text {. Declividade entre } 5 \text { e } 20 \% \text {. Nas } \\
\text { Vales abertos em V. Altitude varia entre } 10 \text { e } 90 \mathrm{~m} \text {. } \\
\text { áreas de vale, a declividade pode } \\
\text { alcançar } 45 \% \text { declividade entre } 5 \text { e } 20 \% \text {. Nas áreas de vale, a }\end{array}$ \\
\hline Solos & $\begin{array}{l}\text { Argissolos desenvolvidos no Grupo Barreiras, em rochas cristalinas ou sob influência destas. } \\
\text { Baixa ou muito baixa fertilidade natural. Espodossolos muito pobres em nutrientes minerais. } \\
\text { Textura arenosa predominante. Latossolos muito intemperizados, profundos e bem drenados. } \\
\text { Baixa e alta fertilidade natural. }\end{array}$ \\
\hline Precipitação & Precipitação entre 195,0 e 205,0 mm no verão e 29,0 e 31,0 mm no inverno. \\
\hline Cobertura vegetal & $\begin{array}{c}\text { Formação arbustivo-herbácea (moitas menores), formação arbustivo-herbácea densa (moitas } \\
\text { densas), arbóreo-arbustiva. }\end{array}$ \\
\hline Uso e ocupação & Solo exposto, pastagem, áreas agrícolas e água. \\
\hline Função geológica & $\begin{array}{l}\text { Emissora e transmissora de matéria e Emissora de matéria e energia. } \\
\text { energia. }\end{array}$ \\
\hline
\end{tabular}

Fonte: Organizada pelos autores (2019).

Sobre o uso e cobertura da terra, foram identificadas áreas com formação arbustivo-herbácea (moitas menores), formação arbustivo-herbácea densa (moitas densas), arbóreo-arbustiva, vegetação em áreas úmidas, solo exposto, pastagem, áreas agrícolas e água. Como similaridade marcante, há presença de extensas áreas de pastagem, que podem potencializar a ocorrência de processos erosivos, e a diferença existente no uso refere-se às áreas agrícolas situadas nas Colinas baixas e Colinas baixas dissecadas.

A Unidade Geoambiental Colinas altas dissecadas apresenta os locais mais preservados de vegetação nativa na zona de amortecimento. São áreas localizadas em topos de morros e em declividades acima de $35 \%$. Já nas Colinas baixas ocorrem as maiores áreas de pastagem, consequentemente a cobertura vegetal não minimiza o impacto das gotas de chuva e, concomitante a esse cenário, a declividade acima de $20 \%$ favorece processos erosivos que podem ocorrer na forma de salpicamento e escoamento superficial, principalmente.

Os processos erosivos decorrem da relação de diferentes características, entre elas a precipitação. Nas Colinas altas, predominam precipitações entre 195 e 205,5 mm nos meses de verão e de 29 a $30 \mathrm{~mm}$ em meses de inverno, e, nas Colinas baixas, predominam precipitações entre 185 e $195 \mathrm{~mm}$ no verão e entre 29 e $30 \mathrm{~mm}$ no inverno. Com esse regime, os meses de verão são propensos a dinamizar processos erosivos, com consequente perda de solo nas colinas e inundação das planícies. 
A água da precipitação, ao entrar em contato com o solo, escoa pela rede de drenagem de padrão dendrítico das colinas, com canais de até $4^{\mathrm{a}}$ ordem. Essa rede de drenagem insere-se nos compartimentos geomorfológicos Colinas altas e Colinas altas dissecadas, com padrão de formas topos convexos e vales abertos e em V, com altitude variando de 90 a $140 \mathrm{~m}$ e declividade de 5 a $20 \%$. Nas Unidades Geoambientais Colinas baixas e Colinas baixas dissecadas, ocorre o compartimento Colinas baixas, com altitude variando de 10 a 90 m e declividade de 5 a $20 \%$.

Quanto à função geoecológica, as unidades Colinas altas dissecadas e Colinas baixas dissecadas são emissoras de matéria e energia. A emissão justifica-se pela altitude mais elevada, por declividades acentuadas, solos rasos, uso e cobertura predominante de pastagens e pluviosidade. Especificamente nas Colinas baixas dissecadas, ocorrem áreas de topos onde a vegetação natural foi suprimida. Por sua vez, as unidades Colinas altas e Colinas baixas são emissoras e transmissoras de matéria e energia. A diferença fundamental da função geoecológica das Colinas altas dissecadas para as Colinas altas e das Colinas baixas dissecadas para as Colinas baixas relaciona-se à transmissão de matéria e energia. Essa característica decorre da posição inferior no relevo das Colinas altas e Colinas baixas, cuja declividade é moderada, em torno de $20 \%$.

Na Tabela 2 são descritas as principais características das Unidades Geoambientais localizadas predominantemente na planície litorânea: Área de inundação, Planície fluviolacustre e Complexo de lagoas paralelas à Praia.

Tabela 2: Características das Unidades Geoambientais Área de inundação, Planície fluviolacustre e Complexo de lagoas paralelas à costa da zona de amortecimento e do PARNA da Restinga de Jurubatiba.

\begin{tabular}{|c|c|}
\hline & Planície fluviolacustre \\
\hline Formações geológicas & $\begin{array}{c}\text { Depósitos fluviolagunares: Depósitos Quaternários, formados } \\
\text { por material carreado pelos rios. }\end{array}$ \\
\hline $\begin{array}{l}\text { Compartimento } \\
\text { geomorfológico }\end{array}$ & $\begin{array}{l}\text { Planície lacustre, Planície fluviolacustre, Planície fluvial. } \\
\text { Relevo plano. Altitude máxima } 10 \mathrm{~m} \text {. Declividade entre } 0 \text { e } \\
\text { 8\%. Forma predominante: cordões litorâneos paralelos à linha } \\
\text { de costa e planície de sedimentos e origem fluviomarinha. }\end{array}$ \\
\hline
\end{tabular}

\begin{tabular}{llr} 
Complexo & \multicolumn{1}{c}{ de } & lagoas \\
paralelas à costa & \\
\hline $\begin{array}{l}\text { Depósitos } \\
\text { marinhos }\end{array}$ & ou & $\begin{array}{r}\text { eólicos, } \\
\text { lagunares: }\end{array}$ \\
$\begin{array}{l}\text { Depósitos } \\
\text { formados Quaternários, }\end{array}$ & por material
\end{tabular}
carreado pelos rios, ventos e dinâmica marinha.

Planície lacustre, Planície fluviolacustre. Relevo plano. Altitude máxima $10 \mathrm{~m}$. Declividade entre 0 e $8 \%$. Forma predominante: cordões litorâneos paralelos à linha de costa, planície de entulhamento de sedimentos e de origem fluviomarinha.

Gleissolos ocorrem predominantemente em áreas alagadas ou sujeitas a alagamentos, com tonalidades acinzentadas, azuladas ou esverdeadas. Organossolos caracterizados pela marcante

Solos saturação d'água na maior parte do tempo, pois ocorrem em regiões baixas e alagadas, geralmente planícies de inundação de rios e córregos.

Precipitação Precipitação entre 165,0 e 195,0 mm no verão e 29,0 e 30,9

Precipitação entre 149,1 e mm no inverno.

$185,0 \mathrm{~mm}$ no verão e de 27,3 a $29,5 \mathrm{~mm}$ no inverno.

Cobertura vegetal Vegetação em áreas úmidas, formação arbustivo-herbácea (moitas menores), arbóreo-arbustiva.

Uso e ocupação

Função geológica

\section{Solo e água.}

Transmissora de matéria e Receptora e transmissora de Receptora e transmissora de energia. matéria e energia. matéria e energia. Fonte: Organizada pelos autores (2019).

As Unidades Geoambientais Áreas de inundação, Planície fluviolacustre, Complexo de lagoas paralelas à costa na área de Planície marinha diferenciam-se das colinas pelo ambiente de formação, e têm como características singulares baixa declividade, cobertura vegetal de restinga arbóreo-arbustiva e arbustivoherbácea, padrão de drenagem em treliça e solos pobres em nutrientes.

$\mathrm{Na}$ Área de inundação e na Planície fluviolacustre, as formações geológicas predominantes são os depósitos fluviolagunares, sedimentos transportados pela rede de drenagem com destino à deposição nas lagoas costeiras de origem fluvial. Nessas unidades, predominam declividades de até $8 \%$ e padrão de forma 
de cordões litorâneos. O solo apresenta alta concentração de matéria orgânica e é, em geral, saturado, devido ao alagamento constante, o que dificulta o uso. São exemplos os Gleissolos pouco húmico álico e os Organossolos Tiomórficos.

Por serem solos saturados por água e com baixa declividade, ocorrem lagoas costeiras e áreas de alagamento nos cordões litorâneos, concentrando-se nos retrocordões. Essa drenagem está intrinsecamente relacionada às características litológicas e climáticas da área. Nas planícies, predomina precipitação entre 165 e $195 \mathrm{~mm}$ nos meses de verão e de 29 a $30,89 \mathrm{~mm}$ em meses de inverno, com inundação de áreas próximas às lagoas em períodos chuvosos.

Além das inundações, a maior pluviosidade, que alcança $204 \mathrm{~mm}$ no verão, possibilita o acúmulo de sedimentos nas áreas de inundação, mudando a coloração da água, devido à maior concentração de partículas em suspensão. A unidade Área de inundação ocorre no entorno das lagoas e áreas de várzea. São locais com dinâmica temporal variável da lâmina d'água, resultado basicamente da precipitação.

Nessas unidades, foram identificadas as seguintes classes de uso e cobertura: vegetação em área úmida, formação arbustivo-herbácea (moitas menores), arbóreo-arbustiva, solo exposto e água. Essas classes têm área variável, de acordo com o período do ano, devido à oscilação natural da lâmina d'água.

Quanto à função geoecológica, as duas unidades diferenciam-se: as Áreas de inundação têm função de transmissão de matéria e energia, enquanto as Planícies fluviolacustres têm função receptora e transmissora de matéria e energia. A diferença fundamental da função geoecológica é que as áreas de inundação são locais com declividade entre 8 e $20 \%$, nos quais a matéria não acumula e a energia não se mantém, mas são transmitidas para as áreas mais baixas, como as Planícies fluviolacustres, nas quais o sedimento se acumula, mas pode ser transmitido, porque essas áreas apresentam capacidade de mobilização e transporte dos sedimentos, devido à dinâmica temporal da sua lamina d'água.

Nas Unidades Geoambientais Complexo de lagoas paralelas à costa, as formações geológicas correspondem a depósitos praiais, eólicos, marinhos e/ou lagunares, de origem fluviomarinha, formando um ambiente sedimentar originado das flutuações marinhas do Quaternário e dando origem aos compartimentos geomorfológicos Planície lacustre, Planície fluviolacustre, Planície fluvial e cordões litorâneos, onde ocorre declividade de no máximo $8 \%$.

O Complexo de lagoas paralelas à costa tem origem relacionada aos antigos níveis do mar. Em alguns locais, foi possível observar, em trabalho de campo, a presença de bovinos pastando nas áreas de brejo formadas pela diminuição da lâmina d'água.

Os solos encontrados são os Espodossolos Hidromórficos distróficos, de ocorrência em relevos suavemente ondulados. Esse tipo de solo facilita o pastoreio, mas dificulta a agricultura, porque necessita de corretivo, devido à sua baixa disponibilidade em nutrientes minerais. Os solos do tipo Gleissolo pouco húmico álico ocorrem em áreas planas alagadas ou sujeitas a alagamentos, têm elevada presença de matéria orgânica, e seu uso é limitado pela presença da umidade, que, na área, é predominantemente de lagoas costeiras de forma paralela ou perpendicular à linha de costa e drenagem com padrão treliça, e as intervenções antrópicas nessas áreas foram responsáveis por abrir canais artificiais, utilizados para escoar a água parada de propriedades.

A maior presença de canais de drenagem está relacionada às áreas de retrocordões, onde localizam-se a maior parte das pequenas lagoas, em forma predominantemente paralela à Praia. Essa drenagem está intrinsecamente ligada às características litológicas e climáticas da área. Nas planícies, predomina precipitação entre 149 e $195 \mathrm{~mm}$ nos meses de verão e 27 e $30 \mathrm{~mm}$ em meses de inverno.

O regime de precipitação auxiliou no desenvolvimento da cobertura vegetal na unidade Complexo de lagoas paralelas à costa. Foram identificadas áreas com vegetação em áreas úmidas, formação arbustivoherbácea (moitas menores), formação arbustivo-herbácea densa (moitas maiores), arbóreo-arbustiva e água relacionadas à cobertura natural de restinga e às classes pastagem, solo exposto, concentradas ao norte da zona de amortecimento e relacionadas ao uso predominante na área desde o século XVIII.

A função geoecológica do Complexo de lagoas paralelas à costa é de recepção e transmissão de matéria e energia, favorecendo o acúmulo de matéria e energia por maior período de tempo.

$\mathrm{Na}$ Tabela 3, são descritas as principais características das Unidades Geoambientais Planície fluviomarinha, Planície marinha, Planície lacustre e Praia. 
Tabela 3: Características das Unidades Geoambientais Planície fluviomarinha, Planície marinha, Planície lacustre e Praia da zona de amortecimento e do PARNA da Restinga de Jurubatiba.

\begin{tabular}{|c|c|c|}
\hline & Planície fluviomarinha & Planície marinha \\
\hline Formações geológicas & \multicolumn{2}{|c|}{$\begin{array}{l}\text { Depósitos praiais marinhos e/ou lagunares: Depósitos Quaternários, formados por dinâmica } \\
\text { marinha e carreados pelos rios. }\end{array}$} \\
\hline $\begin{array}{l}\text { Compartimento } \\
\text { geomorfológico }\end{array}$ & $\begin{array}{l}\text { Planície lacustre, Planície fluviolacustre, } \\
\text { Planície fluvial. Relevo plano. Altitude } \\
\text { máxima } 10 \mathrm{~m} \text {. Declividade entre } 0 \text { e } 8 \% \text {. } \\
\text { Forma predominante: cordões litorâneos } \\
\text { paralelos à linha de costa, vales abertos e } \\
\text { planície de origem fluviomarinha. }\end{array}$ & $\begin{array}{l}\text { Planície lacustre, Planície fluviolacustre, } \\
\text { Planície fluvial. Relevo plano. Altitude } \\
\text { máxima } 10 \mathrm{~m} \text {. Declividade entre 0 e } 8 \% \text {. } \\
\text { Forma predominante: cordões litorâneos } \\
\text { paralelos à linha de costa e planície de } \\
\text { entulhamento de sedimentos de origem } \\
\text { marinha. }\end{array}$ \\
\hline Solos & \multicolumn{2}{|c|}{$\begin{array}{c}\text { Gleissolos ocorrem predominantemente em áreas alagadas ou sujeitas a alagamentos, com } \\
\text { tonalidades acinzentadas, azuladas ou esverdeadas. Espodossolos geralmente muito pobres } \\
\text { em nutrientes minerais com textura arenosa predominante. }\end{array}$} \\
\hline Precipitação & $\begin{array}{l}\text { Precipitação entre } 185,0 \text { e } 204,6 \mathrm{~mm} \text { no verão } \\
\text { e de } 29,51 \text { a } 30,89 \mathrm{~mm} \text { no inverno. }\end{array}$ & $\begin{array}{l}\text { Precipitação entre } 149,1 \text { e } 185,0 \mathrm{~mm} \text { no verão } \\
\text { e de } 27,3 \text { a } 29,5 \mathrm{~mm} \text { no inverno. }\end{array}$ \\
\hline Cobertura vegetal & \multicolumn{2}{|c|}{$\begin{array}{c}\text { Vegetação em áreas úmidas, formação arbustivo-herbácea (moitas menores), formação } \\
\text { arbustivo-herbácea densa (moitas maiores), arbóreo-arbustiva. }\end{array}$} \\
\hline Uso e ocupação & \multicolumn{2}{|c|}{ Áreas agrícolas, pastagem, solo exposto e água. } \\
\hline Função geológica & \multicolumn{2}{|c|}{ Receptora e transmissora de matéria e energia. } \\
\hline & Planície lacustre & Praia \\
\hline $\begin{array}{l}\text { Formações } \\
\text { geológicas }\end{array}$ & \multicolumn{2}{|c|}{$\begin{array}{ll}\text { Depósitos lagunares: Depósitos Quaternários } & \text { Depósitos praiais marinhos: Depósitos } \\
\text { formados pela dinâmica marinha, sedimentos } & \text { Quaternários, formados por material carreado } \\
\text { fluviais depositados nesta área. } & \text { pelos rios e trabalhados pela dinâmica } \\
\text { marinha. } & \end{array}$} \\
\hline $\begin{array}{l}\text { Compartimento } \\
\text { geomorfológico }\end{array}$ & \multicolumn{2}{|c|}{$\begin{array}{l}\text { Relevo plano. Altitude máxima } 10 \mathrm{~m} \text {. } \\
\text { Declividade entre } 0 \text { e } 8 \% \text {. Forma Terraços holocênicos com degraus formados } \\
\text { predominante: planície de entulhamento de devido à intensidade das ondas. } \\
\text { sedimentos. }\end{array}$} \\
\hline Solos & $\begin{array}{l}\text { Organossolo Tiomórfico: caracterizado pela } \\
\text { marcante saturação d'água na maior parte do } \\
\text { tempo. Ocorre em regiões baixas e alagadas, } \\
\text { geralmente planícies de inundação de rios e } \\
\text { córregos. }\end{array}$ & $\begin{array}{l}\text { Solo arenoso com elevado teor de areia e } \\
\text { sedimentos pouco selecionados. }\end{array}$ \\
\hline Precipitação & \multirow{2}{*}{$\begin{array}{l}\text { Precipitação entre } 165,0 \text { e } 185,0 \mathrm{~mm} \text { no verão } \\
\text { e de } 29,0 \text { a } 30 \mathrm{~mm} \text { no inverno. } \\
\text { Vegetação em áreas úmidas, formação } \\
\text { arbustivo-herbácea (moitas menores). }\end{array}$} & $\begin{array}{l}\text { Precipitação entre } 149,1 \text { e } 204,6 \mathrm{~mm} \text { no verão } \\
\text { e de } 27,3 \text { a } 30,9 \text { mm no inverno. }\end{array}$ \\
\hline Cobertura vegetal & & Ausência de vegetação \\
\hline Uso e ocupação & Pastagem, solo exposto e água. & Solo exposto. \\
\hline Função geológica & Receptora de matéria e energia. & $\begin{array}{l}\text { Receptora e transmissora de matéria e } \\
\text { energia. }\end{array}$ \\
\hline
\end{tabular}

Fonte: Organizada pelos autores (2019).

Nas Unidades Geoambientais Planície fluviomarinha e Planície marinha, ocorrem formações geológicas relacionadas a depósitos praiais, eólicos, marinhos e/ou lagunares, de origem fluviomarinha, originados pelas flutuações marinhas do Quaternário, e compartimentos geomorfológicos Planície fluvial e cordões litorâneos, com declividade de no máximo $8 \%$.

Os solos predominantes são os Gleissolos e Espodossolos de ocorrência em áreas sujeitas a alagamentos e com textura arenosa e baixa fertilidade. Em relação à precipitação, devido à localização longitudinal distinta das duas Unidades Geoambientais, são registrados volumes de precipitação entre 185 e 204,6 mm na Planície fluviomarinha e entre $149,1 \mathrm{~mm}$ e $185 \mathrm{~mm}$ na Planície marinha.

As áreas da Planície fluviomarinha são ocupadas, em grande parte, por vegetação arbóreo-arbustiva. Quanto mais próxima aos canais fluviais, braços de lagoas e lagoas, a vegetação é crescente e densa, com ocorrência de formações arbustivo-herbáceas (moitas menores) e formações arbustivo-herbáceas densas (moitas maiores). Nessa unidade e na Planície marinha, estão localizados os balneários de Carapebus, João Francisco e Visgueiro. Já na área de Planície marinha, há presença de plantações de coco e pastagem, até 
próximo ao limite do parque, uso favorecido pela topografia plana da área.

Em referência à função geoecológica, as unidades Planície fluviomarinha e Planície marinha têm função de recepção e transmissão de matéria e energia. São áreas que favorecem o acúmulo desses elementos por maior período de tempo. Os sedimentos podem ser transportados para outros locais com a abertura da barra da Praia, entendendo barra como a porção emersa de sedimentos na linha de contato entre mar e lagoa, e pela variação natural da drenagem nos períodos chuvosos e secos.

Por sua vez, as Unidades Geoambientais Planície lacustre e Praia diferenciam-se das demais e entre si, devido à sua composição e evolução. Na Planície lacustre, as formações geológicas são oriundas de depósitos lagunares, formados pela dinâmica marinha quaternária, onde foi delimitado o compartimento geomorfológico Planície lacustre, com declividade inferior a 8\%. Nesse ambiente, o solo encontrado é do tipo Organossolo Tiomórfico, o mesmo encontrado nas unidades Área de inundação, Planície fluviolacustre e Complexo de lagoas paralelas à costa, por ser uma área de deposição, onde a matéria orgânica se acumula e dá a cor escura característica desse solo.

A Unidade Geoambiental Praia distingue-se das restantes pela alta variação temporal da sua forma, com formação geológica de depósitos praiais marinhos, constituídos por areias quartzosas marinhas com granulometria de fina a média, sem uniformidade de tamanho e com presença de degraus formados pela intensidade das ondas. É a mais dinâmica da área de estudo, por receber a influência das condições atmosféricas e do oceano e ser constituída por material sedimentar com baixa coesão. Na Praia, são encontradas formações geológicas referentes a antigas lagoas, relacionadas a antigas linhas de costa, em período de regressão marinha.

Sobre a drenagem da Unidade Geoambiental Planície lacustre, o padrão treliça é o predominante, e muitos canais são de origem antrópica, além da Lagoa do Ribeira. A drenagem está intrinsecamente ligada às características litológicas e climáticas da área. Nas planícies, predomina precipitação entre 165 e $185 \mathrm{~mm}$ nos meses de verão e de 29 a $30 \mathrm{~mm}$ em meses de inverno.

As classes de uso e cobertura da terra predominantes são Vegetação em áreas úmidas e Pastagem, que ocorrem porque a matéria orgânica dos Organossolos potencializa seu desenvolvimento. Assim, em períodos de seca, o gado avança sobre a planície, buscando novas áreas de vegetação.

A função geoecológica da Unidade Geoambiental Planície lacustre é de recepção de matéria e energia de locais mais altos ao redor, que são trabalhados e depositados nesta planície.

Já a Unidade Geoambiental Praia distribui-se de forma alongada por toda a área de estudo. A precipitação tem, no verão, amplitude de $55 \mathrm{~mm}$ (de 149 a 204,5 mm) e de 3,5 mm (de 27,3 a 30,8 mm) no inverno. Essa Unidade Geoambiental tem a função geoecológica de recepção e transmissão de matéria e energia, visto que seu contato constante com a dinâmica atmosférica e oceânica mobiliza matéria e energia, transportando-os para outros locais.

A análise da paisagem aqui apresentada considerou uma abordagem sistêmica, com o objetivo de delimitar Unidades Geoambientais nas quais as características naturais e de uso e cobertura são semelhantes. Essa abordagem de análise é importante em estudos com foco na gestão territorial, porque subsidiam os projetos que buscam disciplinar regras de uso e ocupação de uma área, como o PARNA da Restinga de Jurubatiba. Essa abordagem tem sido amplamente utilizada em estudos acadêmicos, como o de Amorim e Oliveira (2008), que identificaram e caracterizaram agentes e processos físico-ambientais no município de São Vicente, SP, para propor a delimitação de unidades da paisagem que representavam as fragilidades ambientais potencializadas pela dinâmica e ocupação da área. Por sua vez, Dantas et al. (2005) propuseram um diagnóstico geoambiental para o Estado do Rio de Janeiro, a partir da análise dos componentes da paisagem para a delimitação das Unidades Geoambientais. Diniz e Oliveira (2018) recomendaram a delimitação de Unidades Geoambientais para o Estado do Rio Grande do Norte como etapa preliminar do zoneamento ecológico-econômico, e Robaina e Trentin (2019) desenvolveram um estudo geoambiental no município de São Francisco de Assis, RS, no qual foram delimitadas Unidades Geoambientais com foco no planejamento territorial.

Os trabalhos citados sobre abordagem de análise da paisagem estão embasados na Teoria Geral dos Sistemas, fundamental para o desenvolvimento de estudos que integram diferentes características do ambiente e da sociedade. É necessário considerar que esta abordagem, para fins de planejamento territorial, é desenvolvida em escalas diversas, de acordo com a base de dados disponível. Com a definição da escala, é dada ênfase a determinada potencialidade e fragilidade ambiental da paisagem.

No PARNA da Restinga de Jurubatiba, devido à disponibilização da base cartográfica na escala 1:50.000, foi possível desenvolver um estudo que delimitou Unidades Geoambientais que representam características 
de evolução da paisagem singulares. Com o entendimento da evolução e características da paisagem, é possível subsidiar planos de gestão da unidade de conservação com o objetivo de manter o equilíbrio ambiental da área.

\section{Considerações finais}

A análise da paisagem, por meio de uma visão sistêmica, embasa a proposta de Geoecologia das paisagens de Rodriguez et al. (2004), a qual propõe uma análise considerando as interações de suas características em uma sequência de etapas necessárias para a construção do estudo ambiental com vistas ao planejamento territorial. Nesse contexto, o plano de manejo descreve as características naturais: geologia, geomorfologia, pedologia, recursos hídricos, clima, vegetação e fauna; as características de ocupação humana, por meio do uso e cobertura; e as características culturais da população e econômicas da unidade de conservação e de sua zona de amortecimento. Além de propor um zoneamento para o limite do PARNA, desconsiderando a zona de amortecimento e criando zonas com vistas ao manejo adequado da unidade de conservação, com base em Galante et al. (2002).

Com esse procedimento, são orientadas atividades de uso internas na unidade de conservação, mas ao desconsiderar a zona de amortecimento, também é negligenciada sua importância para a estabilidade ambiental no interior do PARNA, visto que a paisagem evolui de maneira integrada e qualquer mudança fora dos limites da unidade de conservação afeta consequentemente o interior do PARNA, por exemplo, o aumento de áreas de solo exposto resulta em maior transporte de sedimentos para os rios e córregos que desaguam nas lagoas costeiras do PARNA, assoreando-as; além do despejo de esgoto que ocorre no canal Campos-Macaé que passa, igualmente, pelo interior do PARNA, que afeta o equilíbrio biológico das lagoas.

Outro ponto a ser destacado é que as características físicas de evolução da paisagem são descritas e analisadas de maneira sistêmica, como proposto neste estudo, e podem contribuir para o planejamento territorial.

Para tanto, este artigo busca contribuir delimitando as Unidades Geoambientais que representam a evolução da paisagem, mapeamento que pode ser integrado ao planejamento da unidade de conservação, oferecendo uma visão sistêmica e integrada da paisagem e, consequentemente, da proteção da área de restinga, objetivo da delimitação dessa unidade de conservação.

As Unidades Geoambientais delimitadas localizam-se em duas formas de relevo distintas, as colinas e a planície litorânea, ambientes formados por processos diversos, mas interligados, que evoluem concomitantemente.

Considerando o potencial do relevo para redistribuir matéria e energia, os gestores do PARNA da Restinga de Jurubatiba devem ponderar que modificações ocorridas na zona de amortecimento podem afetar a estabilidade natural do ambiente interno do PARNA, visto que sua criação foi baseada na preservação do sistema lagunar e do ecossistema restinga.

$\mathrm{Na}$ zona de amortecimento, encontram-se as principais Unidades Geoambientais emissoras de matéria e energia para locais com cotas mais baixas. A falta de cobertura vegetal densa acaba por potencializar processos erosivos e, consequentemente, a deposição desses sedimentos na Planície litorânea, onde se encontram as lagoas costeiras protegidas pelo PARNA.

Já na Planície litorânea, encontram-se as Unidades Geoambientais responsáveis por receber e transmitir matéria e energia. Sua composição sedimentar facilita o deslocamento dos sedimentos com maior facilidade, e os agentes esculturadores, como o clima, tornam esses ambientes mais instáveis.

Para minimizar e regular o uso e a ocupação do território, com vistas ao equilíbrio ambiental, a delimitação de Unidades Geoambientais segmentando o território em unidades com características semelhantes é uma proposta passível de ser aplicada. Nesse contexto, a metodologia aqui apresentada, por considerar diferentes características, tem uma visão holística da paisagem, entendendo o seu funcionamento e os processos atuantes.

\section{Referências}

AB'SABER, A. N. Fundamentos da geomorfologia costeira no Brasil Atlântico inter e subtropical. Revista Brasileira de Geomorfologia, v. 1, n. 1, 27-43, 2000. 
AMORIM, R. R.; OLIVEIRA, R. C. As unidades de paisagem como uma categoria de análise geográfica: o exemplo do município de São Vicente-SP. Sociedade e Natureza (Online), Uberlândia, v. 20, n. 2, 177-198, 2008. DOI: $10.1590 / \mathrm{S} 1982-45132008000200011$.

ARGENTO, M. S. F. Mapeamento geomorfológico. In: GUERRA, A. T.; CUNHA, S. B. (Orgs.) Geomorfologia: uma atualização de bases e conceitos. 2ed. Rio de Janeiro: Bertrand Brasil, 1995. p. 365392.

BERNARDES, L. M. C. Planície litorânea e zona canavieira do Estado do Rio de Janeiro. Guia da excursão $n^{0} 5$ realizada por ocasião do XVIII Congresso Internacional de Geografia. 1957.

BRASIL. Lei 9.985, de 18 de jul. 2000 - Regulamenta o art. 225, § 1o, incisos I, II, III e VII da Constituição Federal, institui o Sistema Nacional de Unidades de Conservação da Natureza e dá outras providências. Brasília, DF: Senado, 2000.

CARVALHO FILHO, A.; LUMBRERAS, J. F.; SANTOS, R. D. Os solos do Estado do Rio de Janeiro. Rio de Janeiro: CPRM, 2001.

CONAMA - Conselho Nacional de Meio Ambiente. Resolução no 13, de 06 de dezembro de 1990. Publicada no D.O.U. de 28/12/90, Seção I, Pág. 25-541, Brasília, DF. 1990.

CONCEIÇÃO, A. F.; FOLHARINI, S. O.; ANDRADE, R. G.; FURTADO, A. L. S. Dinâmica de uso e cobertura das terras no Parque Nacional da Restinga de Jurubatiba e sua zona de amortecimento, RJ. In: V SIGA CIÊNCIA - SIMPÓSIO CIENTÍFICO DE GESTÃO AMBIENTAL, 2016, Piracicaba. Anais... Piracicaba: USP, 2016. p. 1-6.

CORDEIRO, M. R.; RODRIGUES, S. M; SOUZA, P. R. N; FERREIRA, M. I. P. Avaliação da contaminação de efluentes domésticos em poços sobre área de restinga. Boletim do Observatório Ambiental Alberto Ribeiro Lamego, v. 5, n. 1, p. 89-102, 2011.

DANTAS, M. E.; SHINZATO, E.; MEDINA, A. I. M.; SILVA, C. R.; PIMENTEL, J.; LUMBRERAS, J. F.; CALDERANO, S. B.; CARVALHO FILHO, A. Diagnóstico Geoambiental do Estado do Rio de Janeiro. In: OFICINA INTERNACIONAL DE ORDENAMENTO TERRITORIAL MINEIRO, 2005, Rio de Janeiro. Anais... Rio de Janeiro, 2005. p.1-12.

DEAN, W. A ferro e fogo: a história e a devastação da Mata Atlântica brasileira. São Paulo: Companhia das Letras, 1996.

DIAKONOV, K. N. Geofísica das paisagens: método dos balances. Moscou: Editora da Universidade Estadual de Moscou, 1988.

DINIZ, M. T. M.; OLIVEIRA, A. V. L. C. Mapeamento das Unidades de paisagem do estado do Rio Grande do Norte, Brasil. Boletim Goiano de Geografia, v.38, n.2, p.342-364, 2018 . DOI: 10.5216/bgg.v38i2.54613.

FEEMA - Fundação Estadual de Engenharia do Meio Ambiente. Perfil ambiental - municípios de Macaé e Quissamã. Rio de Janeiro. 1989.

FOLHARINI, S. O.; FURTADO, A. L. S. Caracterização morfopedológica do Parque Nacional da Restinga de Jurubatiba e sua zona de amortecimento terrestre. In VI CONGRESSO IBEROAMERICANO DE ESTUDIOS TERRITORIALES Y AMBIENTALES, 2014, São Paulo. Anais... São Paulo: USP, 2014, p. $2960-2980$.

FOlHARINI, S. O.; OLIVEIRA, R. C.; FURTADO, A. L. S.; CONCEIÇÃO, A. F. Compartimentação geomorfológica do Parque Nacional da Restinga de Jurubatiba e sua zona de amortecimento terrestre. In: XIV Colóquio Ibérico de Geografia, 2014, Guimarães - Portugal. Anais... Guimarães: Universidade do Minho, 2014. p.2224-2229. 
GAlante, M. L. V.; BeSERRA, M. M. L.; MENEZES, E. O. Roteiro Metodológico de Planejamento: Parque Nacional, Reserva Biológica, Estação Ecológica. Instituto Chico Mendes de Conservação da Biodiversidade: Brasília: Ministério do Meio Ambiente; 2002.

GUERRA, A. J. T.; CUNHA, S. B. Impactos ambientais urbanos no Brasil. 3 ed. Rio de Janeiro: Bertrand, 2005.

IBGE - Instituto Brasileiro de Geografia e Estatística. Censo Demográfico 2010. Disponível em: <https://censo2010.ibge.gov.br/>.

IBGE - Instituto Brasileiro de Geografia e Estatística. Histórico dos municípios brasileiros: Macaé, Carapebus e Quissamã. Rio de Janeiro. 2014. Disponível em: <https://cidades.ibge.gov.br/>.

IBGE - Instituto Brasileiro de Geografia e Estatística. Malhas digitais. 2015. Disponível em: <https://mapas.ibge.gov.br/bases-e-referenciais/bases-cartograficas/malhas-digitais>.

ICMBIO - Instituto Chico Mendes de Conservação da Biodiversidade. Plano de Manejo do Parque Nacional da Restinga de Jurubatiba - Contextualização da Unidade de Conservação. Rio de Janeiro: Ministério do Meio Ambiente, 2007.

KÖPPEN, W. Climatologia: con um estúdio de los climas de la Tierra. México: Fondo de Cultura Economica, 1948.

LAMEGO, A. R. Geologia das quadrículas de Campos, São Tomé, Lagoa Feia e Xéxé. Boletim no 154. Rio de Janeiro: Instituto Brasileiro de Geografia e Estatística, 1955.

LAMEGO, A. R. O homem e a restinga. Rio de Janeiro: Instituto Brasileiro de Geografia e Estatística, 1946.

MARTIN, L.; DOMINGUEZ, J. M. L; SUGUIO, K.; FLEXOR, J. M. Geologia do quaternário costeiro do litoral norte do Rio de Janeiro e do Espírito Santo. Belo Horizonte: CPRM/FAPESP. 1997.

MARTIN, L.; SUGUIO, K; FLEXOR, J. M.; DOMINGUEZ, J. M. L.; AZEVEDO, A. E. G. Evolução da planície costeira do rio Paraíba do Sul (RJ) durante o quaternário: influência das flutuações do nível do mar. In: XXXIII CONGRESSO BRASILEIRO DE GEOLOGIA. Anais... Rio de Janeiro, 1984, p. 84-97.

MMA - Ministério do Meio Ambiente. Imagens RapidEye - Geocatálogo. 2015. Disponível em:

<http://geocatalogo.mma.gov.br/>.

MORAES, A. C. R. Contribuições para a gestão da zona costeira do Brasil: elementos para uma geografia do litoral brasileiro. São Paulo: Annablume, 2007.

MUEHE, D. Erosão costeira, mudança do clima e vulnerabilidade. In: GUERRA, A. J. T.; JORGE, M. C. O. (Orgs.). Processos erosivos e recuperação de áreas degradas. 1 ed. São Paulo: Oficina de Textos, 2013. p. $160-190$.

MUEHE, D. O litoral brasileiro e sua compartimentação. In: GUERRA, A. J. T.; CUNHA, S. B. (Orgs.). Geomorfologia do Brasil. Rio de Janeiro: Bertrand Brasil, 1998.

MUEHE, D.; LIMA, C. F.; LINS DE BARROS, F. M. Erosão e progradação no litoral Brasileiro: Estado do Rio de Janeiro. Brasília: Ministério do Meio Ambiente; 2006.

ROBAINA, L.; TRENTIN, R. Estudos e zoneamento geoambiental do município de São Francisco de Assis - Oeste do Rio Grande do Sul. GOT: Revista de Geografia e Ordenamento do Território. v. 16, 323-344, 2019. DOI: 10.17127/got.v0i16.679.

RODRIGUEZ, J. M. M.; SILVA, E. V.; CAVALCANTI, A. P. B. Geoecologia das paisagens: uma visão geossistêmica da análise ambiental. Fortaleza: Editora da UFC, 2004. 
SANTOS, M. C. Contribuição à gestão das lagoas costeiras: conhecimento tradicional, técnico e científico associado ao manejo dos recursos naturais da Lagoa de Carapebus. Dissertação de Mestrado. Centro Federal de Educação Tecnológica de Campos, 2008.

SILVA, L. A cidade e a floresta: o impacto da expansão urbana sobre áreas vegetadas na Região Metropolitana de São Paulo (RMSP). Tese (doutorado) - Programa de Pós-Graduação em Ciência Ambiental da Universidade de São Paulo, 2013. 269 p.

SOUZA, C. R. G.; MOREIRA, M. G.; LOPES, E. A. Coastal plain and low-medium slope sub-biomes: a new approach based on studies developed in Bertioga (SP). Brazilian Journal of Ecology, v. 8, p. 29-39. 2009.

VILLWOCK, J. A.; LESSA, G. C.; SUGUIO, K.; ANGULO, R. J.; DILLENBURG, S. R. Geologia e Geomorfologia de regiões costeiras. In: SOUZA, C. R. G. (Eds.). Quaternário do Brasil. Ribeirão Preto: Editora Holos. 